論文

박막형 압전재료 $3203 \mathrm{HD}$ 의 재료 비선형성을 고려한 바이모프 보 작동기의 비선형 유한 요소해석

장성훈*, 김영성*, 이상기*, 박훈철**, 윤광준***

\title{
Finite element analysis of the PZT 3203HD bimorph beam actuator based on material non-linear characteristics
}

Sung-Hoon Jang*, Young Sung Kim*, Sang-Ki Lee*, Hoon Cheol Park ${ }^{\star \star}$ and Kwang Joon Yoon ${ }^{\star * *}$

\begin{abstract}
In this paper, material non-linear behavior of PZT wafer(3203HD, CTS) under high electric field and stress is experimentally investigated and the non-linearity of the PZT wafer is numerically simulated. Empirical functions that can represent the non-linear behavior of the PZT wafer have been extracted based on the measured piezo-strain under stress. The functions are implemented in an incremental finite element formulation for material non-linear analysis. New definition of the piezoelectric constant and the incremental strain are incorporated into the finite element formulation for a better reproduction of the non-linear behavior. With the new definition of the incremental piezo-strain, the measured non-linear behavior of the PZT wafer has been accurately reproduced even for high electric field. For validation of the measured non-linear characteristics and the proposed approach, a PZT bimorph beam actuator has been numerically and experimentally tested. The predicted actuation displacement, based on the material nonlinear finite element analysis, showed a good agreement with the measured one.

\section{초 록}

본 논문에서는 고 전압, 고 응력 하에 있는 압전 재료의 재료 비선형 거동을 실험적으로 밝히고, 수치적으로 모사하였다. 응력 하에서, 압전 재료의 비선형 거동을 표현 할 수 있는 실험식을 압전 변형율에서 만들어 내었다. 그 식은 재료 비선형 해석을 위하여, 증분 형태 의 유한요소 식에 적용되었다. 압전 상수에 대한 새로운 정의와 증분 형태로 표현된 압전 변형율이 보다 나은 비선형 거동의 복원을 위하여 유한 요소 정식화과정에 적용 되었다. 이것으로, 높은 전기장 영역에서도, 박판형 압전 재료의 비선형 거동을 정확하게 복원 하였 다. 일련의 수행된 실험과 연구 과정의 검증을 위하여, 압전재료 바이모프 보 작동기가 수 치적으로와 실험적으로 사용되었다. 재료 비선형 유한요소해석으로 예측된 변위와 실험으 로 구해진 변위가 잘 일치함을 확인하였다.
\end{abstract}

Key Words : Material non-linear(재료비선형), PZT wafer(압전재 박판), Piezoelectric constant (압전 상수), Incremental finite element analysis(증분형태의 유한요소해석)

+ 2003년 11월 19일 접수 2004년 2월 7일 심사완료

* 정회원, 건국대학교 항공우주공학과 대학원

** 정회원, 건국대학교 항공우주공학과 I. 서 론 연락저자, E-mail : hcpark@konkuk.ac.kr 서울시 광진구 화양동 1 번지

*** 정회원, 건국대학교 항공우주공학과

최근 스마트 구조의 실현을 위하여, 큰 작동력 과 작동 변위를 낼 수 있는 작동기에 대한 연구 
가 활발히 진행되어 왔다[1-4]. 이러한 연구의 결 과, Bimorphs, RAINBOW, Patches, THUNDER, LIPCA등과 같은 작동기가 개발되어 왔다. 특히, 복합재료[4]로 제작된 LIPCA 작동기는 NASA에 서 개발된 THUNDER[3]보다 가벼우면서도 작동 력과 작동변위가 크게 향상되었다.

Lee 등[5]은 LIPCA의 개발과정에서 가정 변형 률 18절점 솔리드 요소를 이용한 선형 유한요소 해석 프로그램을 개발하여, 작동기의 작동변위를 해석하였으나, 저 전압에서는 작동변위를 잘 예 측할 수 있는 반면에, 고 전압 하에서는 작동변 위를 제대로 예측하지 못함과, 비선형 해석, 특히 재료 비선형 해석이 필요함을 확인하였다.

Crawley 등[6]은 인장하는 압전 재료의 변형율 을 전기장의 함수로 표현하였고, Thornburgh등 [7]은 Crawley [6]의 방법을 적용하여, 재료 비선 형 해석을 수행하여 Wang [8]이 제시한 유니모 프 보 작동기에 대한 실험결과와 비교하였으나, 응력의 영향을 무시하였다. Zhang 등[8]은 압전 재료의 재료 특성이 응력에 영향을 받고 있음을 실험적으로 보였다.

본 논문에서는 압전작동기의 비선형거동의 원 인이, 박막형(wafer) 압전 재료(PZT 3203HD, CTS)의 재료 비선형성에 있다고 판단하여, 사용 된 재료의 실험을 통해 Crawley 등[6]이 제시한 비선형 수식을 변형한 전기장과 응력의 함수로 표현하여, 이 함수를 Lee 등[5]이 개발한 가정변 형률 18 절점 솔리드 프로그램에 적용하여 실험결 과를 수치적으로 모사하여, 압전작동기의 작동변 위의 보다 정확한 예측 가능성을 제시하였다.

\section{II. 압전 재료 비선형 특성 실험}

\section{1 실험 개요}

압전재료(PZT 3203HD, CTS)에 하중을 가하여 기계적인 응력(mechanical stress)을 발생시킨 후 전기장을 가하여 전체 변형률을 측정하였다. 시 편의 크기는 $71 \mathrm{~mm} \times 23 \mathrm{~mm} \times 0.25 \mathrm{~mm}$ 이며, 인장 응 력을 받는 경우에는 Fig. 1 과 같이, 양쪽 끝 부분 에 유리섬유/에폭시(Glass/Epoxy) 탭을 부착하 여 시편의 파괴를 방지하였으며, 압축 응력을 받 는 경우는 Fig. 2의 지그(jig)를 제작하여 실험하 였다.

Fig. 1 의 상단과 하단 탭 (tap)의 크기는 $25 \times 25$ $\times 1.8 \mathrm{~mm}$ 이고, Fig. 2에서 블록(block)형상으로 제작된 4 개의 폴리우레탄 폼(polyurethan foam) 재질의 탭의 크기는 $30 \times 24 \times 10 \mathrm{~mm}$ 이다. 변형률

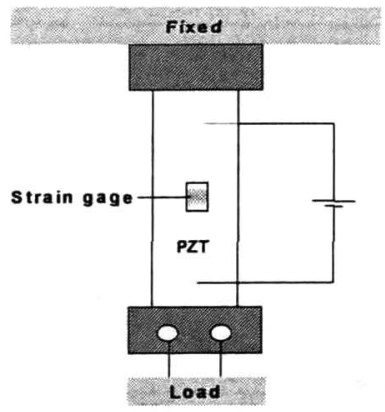

Fig. 1. test for tensile stress

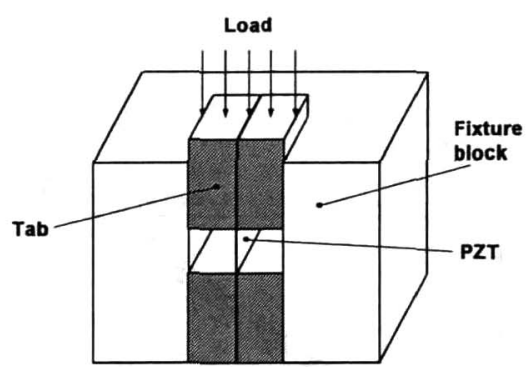

Fig. 2. test for compressive stress

측정을 위해 사용한 스트레인게이지는 Micro -Measurements사의 WK-00-125AD-350이다.

각 시편에 하중을 가하기 위해 하중을 가하는 물체의 무게를 저울을 이용해 측정한 후 인장시 험(Fig. 1)의 경우 시편에 매달고, 압축시험(Fig. 2)의 경우 시편에 얹어 놓는 방법을 이용하였다.

\section{2 실험 방법 및 결과}

압전 재료의 압전 변형률(piezo strain)을 응력 을 먼저 가한 후에 전기장을 가하여 측정하였다. 인장 응력의 경우, 외부하중은 응력이 $1 \mathrm{MPa}$, $2 \mathrm{MPa}, 5 \mathrm{MPa}$, 압축 응력의 경우, 응력이 $1 \mathrm{MPa}$, $5 \mathrm{MPa}, 10 \mathrm{MPa}$ 이 되도록 각각 부가하였으며, 준 정적 상태로 가정하여 실험하였다.

Fig. 3은 외부하중 아래 압전 재료의 평판 (in-plane) 방향으로 변형률이 증가하게 전기장을 가한 실험(이하 CASE 1) 결과이며 분극역전 현 상(polarization switching)이 대략 $700[\mathrm{~V} / \mathrm{mm}]$ 에 서 발생하는 것이 관찰되어 전기장은 600 $[\mathrm{V} / \mathrm{mm}]$ 까지만 가하였다.

압전재료의 경우 폴링 방향(poling direction) 과 동일한 방향으로 전기장을 가하는 경우에는 분극역전이 발생하지 않는다. 그러나 폴링 방향 과 반대로 전기장을 가하는 경우에는 분극역전이 발생하게 된다. 


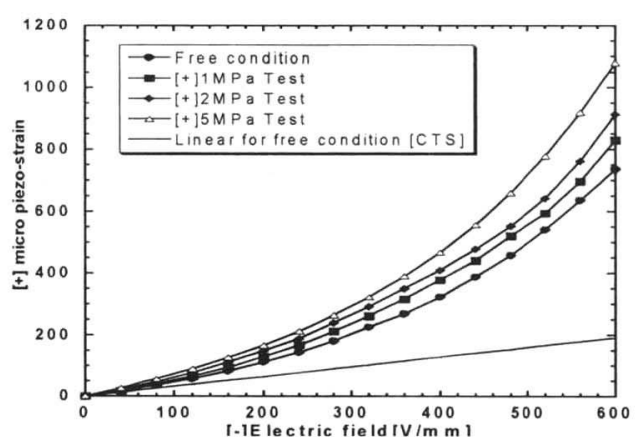

Fig. 3. Piezo-strain vs. electric field under tensile stress(extension case)

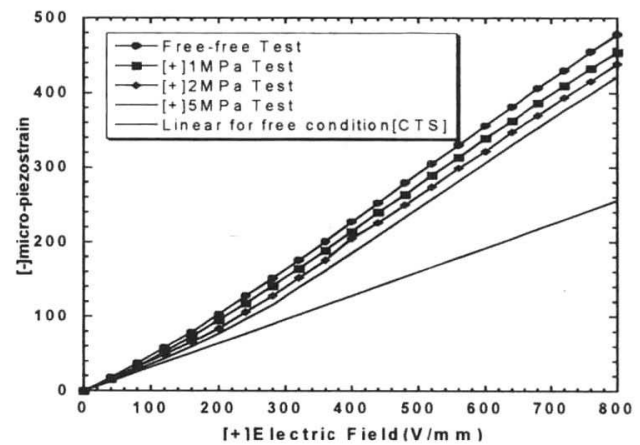

Fig. 4. Piezo-strain vs. electric field under tensile stress(contraction case)

Fig. 4는 평판 방향으로 변형률이 감소하게 전 기장을 가한 결과(이하 CASE 2)이며, 이 경우 분 극 역전 현상은 발생하지 않는다. Fig. 3 의 결과 를 보면, 웅력이 중가함에 따라 발생하는 압전 변형률은 증가하였으며, Fig. 4의 경우는 이와 반 대이다.

Fig. 5와 6은 압축응력 하에서의 실험 결과이 다. 압축 응력하에 있는 Fig. 5 를 보면 응력이 중 가함에 따라 압전 변형율은 감소하며, Fig. 6에서 는 응력에 압전 변형율이 영향을 받지 않는 것으 로 나타났다.

즉, 이상의 결과를 통해, 압전 재료(PZT $3203 \mathrm{HD}$ )를 제작하여 판매하는 CTS사에서 제공 하는 압전 재료의 압전변형률계수(piezoelectric strain coefficient, $d_{31}$ )로는 물리적 거동을 제대로 예측할 수 없음을 확인하였으며, 압전변형률계수 가 전기장뿐만 아니라 응력에 종속되어 있음을 알 수 있다.

본 실험에 사용된 압전 재료(PZT 3203HD)의 압전 변형률을 각각 주어지는 응력에 따라, CASE 1과 CASE 2에 대해 전기장과 응력의 함

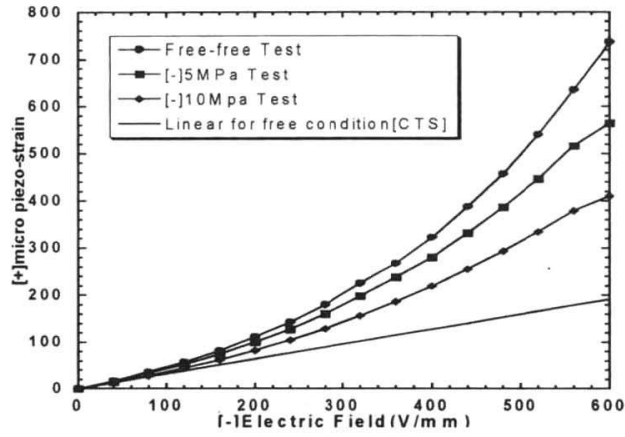

Fig. 5. Piezo-strain vs. electric field under compressive stress(extension case)

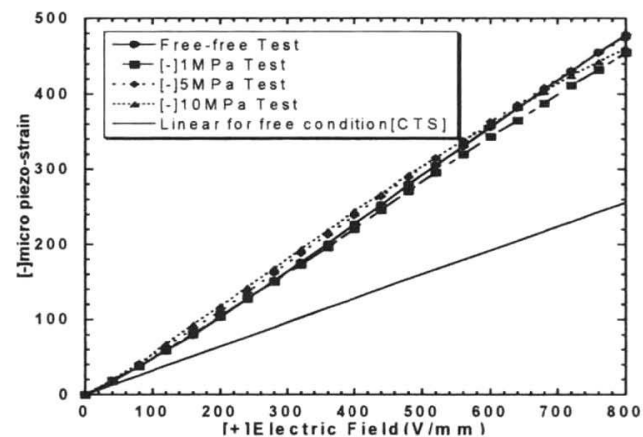

Fig. 6. Piezo-strain vs. electric field under compressive stress(contraction case)

수로 표현하여 다음의 식으로 나타내었다. 식(1), (2)는 인장 응력 하에서, 식(3), (4)는 압축 응력 하의 압전 변형률이다. 이 식들은 Crawley 등[6] 이 제시한 비선형 수식을 변형하여 압전 변형률 을 전기장과 응력의 함수로 표현한 것으로, 측정 데이터를 되도록 간단한 수식으로 보간 (interpolation)할 수 있는 형태로 구했다.

$$
\begin{aligned}
& \varepsilon_{p}=\left(320 \times 10^{-12}+1.34 \times 10^{-10} e^{\left(3.2 \times 10^{-6}\right) E_{p}}\right) E_{p} \\
& \times\left(1+1.4 \times 10^{-7}(\sigma)-1 \times 10^{-14}\left(\sigma^{2}\right)\right) \\
& \varepsilon_{p}=\left(320 \times 10^{-12}+9 \times 10^{-16} E_{p}-7 \times 10^{-22} E_{p}^{2}\right) E_{p} \\
& \times\left[1-\left(3 \times 10^{-27} E_{p}^{2}+2 \times 10^{-21} E_{p}-1 \times 10^{-14}\right) \sigma^{2}\right. \\
&\left.+\left(-7 \times 10^{-20} E_{p}^{2}+6 \times 10^{-15} E_{p}+9.4 \times 10^{-8}\right) \sigma\right] \\
& \varepsilon_{p}=\left(320 \times 10^{-12}+1.34 \times 10^{-10} e^{\left(3.2 \times 10^{-6}\right) E_{p}}\right) E_{p} \\
&+\sigma E_{p}\left[\left(2 \times 10^{-35} \sigma+3 \times 10^{-28}\right) E_{p}^{2}\right. \\
&\left.\quad-\left(1 \times 10^{-29} \sigma+1 \times 10^{-22}\right) E_{p}+1 \times 10^{-17}\right] \\
& \varepsilon_{p}=\left(320 \times 10^{-12}+9 \times 10^{-16} E_{p}-7 \times 10^{-22} E_{p}^{2}\right) E_{p}
\end{aligned}
$$


여기서, $\varepsilon_{p}$ 는 압전변형률을, $E_{p}(\mathrm{~V} / \mathrm{mm})$ 는 전기장을, $\sigma(\mathrm{Pa})$ 는 응력을 의미한다.

\section{III. 압전 변형율의 표현식 검증}

Crawley 등[6]은 실험적으로 측정된 압전변형 률을 식(5)와 같이 표현하였다.

$$
\varepsilon_{p}=A E_{p}+B E_{p}{ }^{2}
$$

식(5)로부터, 압전재료의 압전변형률계수 $\left(d_{31}\right)$ 는 식(6) 또는 식(7)로 정의될 수 있다.

$$
\begin{gathered}
\varepsilon_{p}=\left(A+B E_{p}\right) E_{p}=d_{31} E_{p}, \quad d_{31}=A+B E_{p} \\
d_{31}=\frac{d \varepsilon_{p}}{d E_{p}}=A+2 B E_{p}
\end{gathered}
$$

본 절에서는 Chattopadhyay 등[7]이 사용한 압전재료의 압전변형률계수인 식(6)과 전기장에 대한 압전변형률의 기울기로 표현되는 압전변형 률계수인 식(7)를 각각 Lee 등[5]이 개발한 유한 요소해석 프로그램에 적용하여 전기장의 증분형 태로 가해 얻은 해석값과 측정 변형률을 비교하

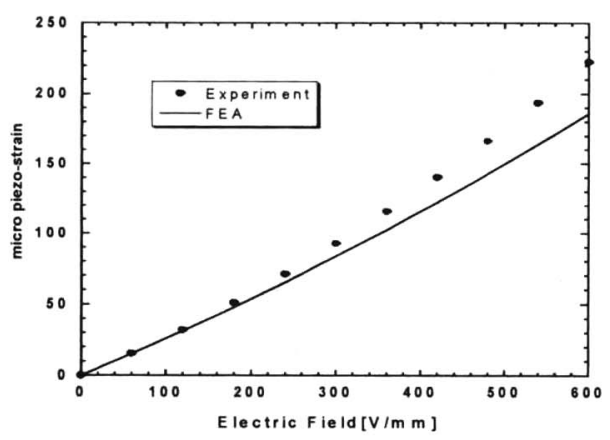

Fig. 7. Reproduction by using $d_{31}=A+B E_{p}$

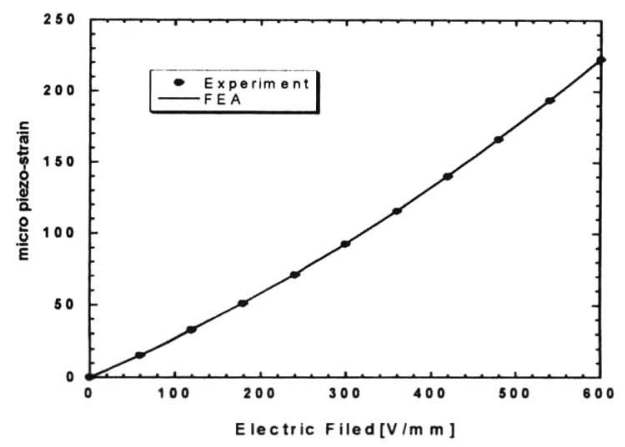

Fig. 8. Reproduction by using $d_{31}=A+2 B E_{p}$
였다. 유한요소 정식화에 대해서는 참고문헌[9]에 자세히 소개되어있어 여기서는 생략한다.

먼저 Crawley 등[6]이 실험적으로 측정한 전기 장만의 함수로 표현된 G1195 압전재료의 압전변 형률과 전기장의 관계식을 이용하여 이용하여 압 전재료의 압전변형률계수( $\left.d_{31}\right)$ 정의인 식(6)과 식 (7)의 타당성을 검토하였다.

Fig. 7은 $d_{31}=A+B E_{p}$ 을 이용하였으며, Fig. 8 은 $d_{31}=A+2 B E_{p}$ 을 이용하여 전기장을 증분 형태로 가한 해석값과 측정 변형률을 비교하였 다. Fig. 7과 Fig. 8에서 보듯이 압전재료의 압전 변형률계수는 압전변형률의 기울기 형태인 $d_{31}=A+2 B E_{p}$ 을 사용해야 함을 알 수 있다.

\section{IV. 압전 변형율의 수치적 모사}

압전변형률이 전기장과 응력의 함수인 식 (1) (4)를 이용하여 Fig. 1 4의 PZT $3203 \mathrm{HD}$ 의 실험결과를 증분 형태의 수치적 방법으로 모사하 기 위해서 식(8)과 같은 확장된 Taylor Series를 사용하였다.

$$
\begin{aligned}
f(x+\Delta x, y+\Delta y) & =f(x, y)+\frac{\partial f(x, y)}{\partial x} \Delta x \\
+ & \frac{\partial f(x, y)}{\partial y} \Delta y+(\text { H.O.T. })
\end{aligned}
$$

식(8)에서 $f, x, y$ 대신 각각 $\varepsilon_{p}, \sigma, E_{p}$ 로 대체하면 식(9)와 같다.

$$
{ }^{i+1} \varepsilon_{p}\left(\sigma, E_{p}\right)={ }^{i} \varepsilon_{p}+\frac{\partial \varepsilon_{p}}{\partial \sigma} \Delta \sigma+\frac{\partial \varepsilon_{p}}{\partial E_{p}} \Delta E_{p}
$$

식(9)를 3절과 동일한 방법으로 Lee 등[5]의 유 한요소해석 프로그램에 적용하여 우선 외력이 없 는 경우에 대해서만 전기장과 응력의 증분형태로

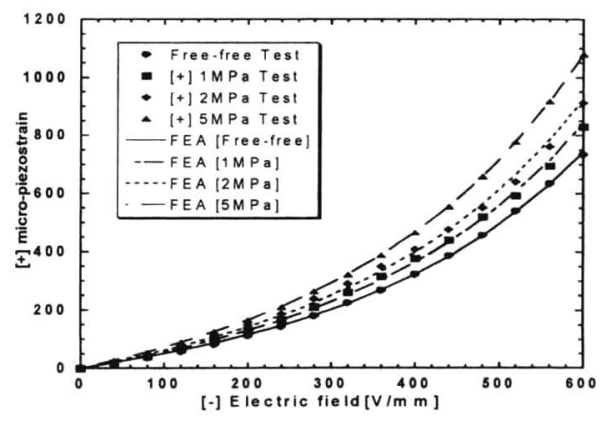

Fig. 9. Comparison between test and analysis result for extension case 


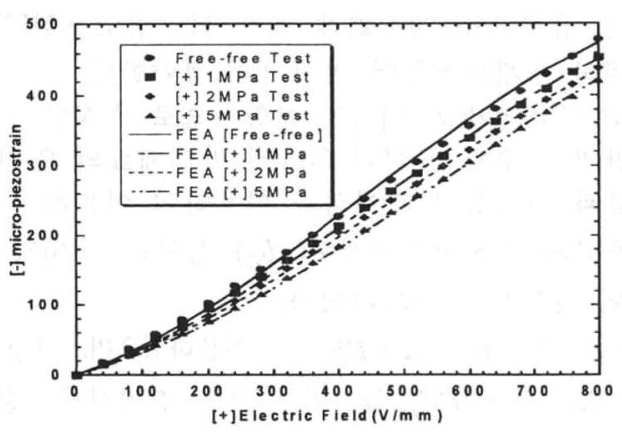

Fig. 10. Comparison between test and analysis result for contraction cse

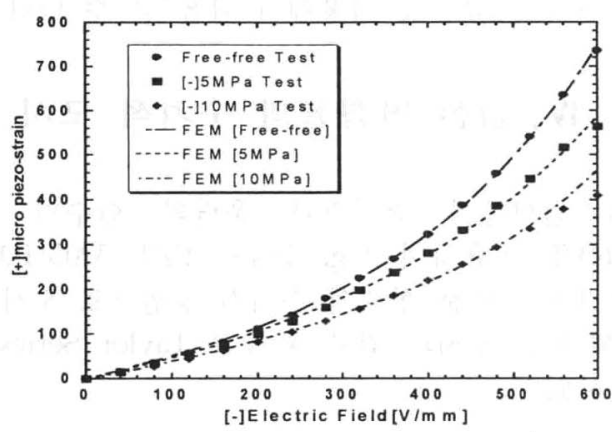

Fig. 11. Comparison between test and analysis result for case 1 under compression

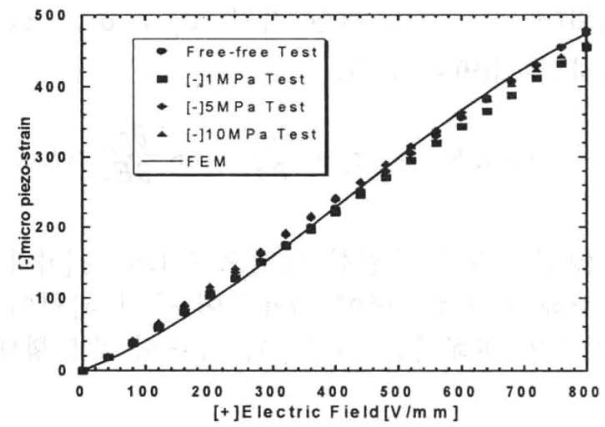

Fig. 12. Comparison between test and analysis result for case 2 under compression

계산한 해석값과 측정변형률을 비교 도시하였으 며, 인장 웅력을 가한 경우에 대해서는 식(1)과 식(2)로 근사한 값과 측정 변형률을 Fig. 9와 10 에, 압축 응력의 경우는 식(3)과 식(4)로 근사한 값과 측정 변형률을 Fig 11과 12에 비교 도시하 였다.

각 그림들에서 보는 바와 같이 증분기법을 이
용한 유한요소해석 결과는 각 실험 결과들과 잘 일치하는 것을 알 수 있다.

\section{V. 수치 예제}

\section{1 실험개요}

지금까지의 방법의 검증을 위하여, 바이모프 보 작동기의 해석을 수치 예제로 해보았다. 이는 바이모프 작동기가 동시에 인장과 압축의 응력 하에서 작동하므로, 이번 연구에서의 수치 예제 로 적당하기 때문이다. 이를 위하여, 앞의 물성치 실험에서 사용된 것과 동일한 압전재료(PZT $3203 \mathrm{HD}, \mathrm{CTS})$ 를 사용하여 작동기를 만들었다. 이를 위해 두 개의 PZT층을 서로 반대의 폴링 방향을 갖도록 접착시켰으며, 접착제는 LOCTITE401을 사용하였다. 실험 시편의 형상은 Fig. 13 과 같고, 시편의 크기는 $71 \times 23 \times 0.5 \mathrm{~mm}$ 이다.

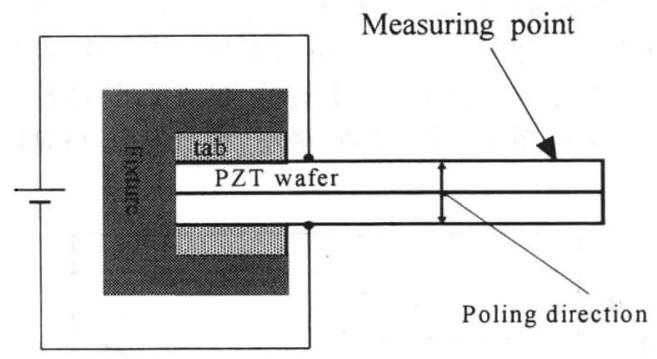

Fig. 13. bimorph beam test

\section{2 실험 결과 및 수치적 모사}

전기장을 $300(\mathrm{~V} / \mathrm{mm})$ 까지 증가시키면서, 끝단 고정점에서 $55 \mathrm{~mm}$ 되는 지점에서의 변위를 측정 하였다. 이때, 레이저 변위 측정기를 사용하여 변 위를 측정하였다.

작동기의 유한요소해석을 위하여, 앞에서 확보 된 재료 비선형함수를 Lee 등[5]이 개발한 가정 변형율 18절점 솔리드 압전 요소에 적용하여 작 동기의 거동을 해석하였다. 요소의 수렴성을 확 인한 결과, 요소 개수가 각각 $\mathrm{x}, \mathrm{y}, \mathrm{z}$ 방향으로, 1 $\times 1 \times 2$ 일 때 수렴된 값을 제시하였다. 측정 변위 와 해석결과는 아래의 Fig. 14에 나타나 있다.

Fig. 14 에서 보듯이, 측정 변위와 해석결과가 약간의 차이를 보이고는 있지만, 선형 해석결과 와 비교해 볼 때 고 전기장 하에서도 두 결과가 잘 일치하는 것을 알 수 있다. 해석값과 실험값 과의 차이는 두 압전재 사이의 접착층에서 발생 


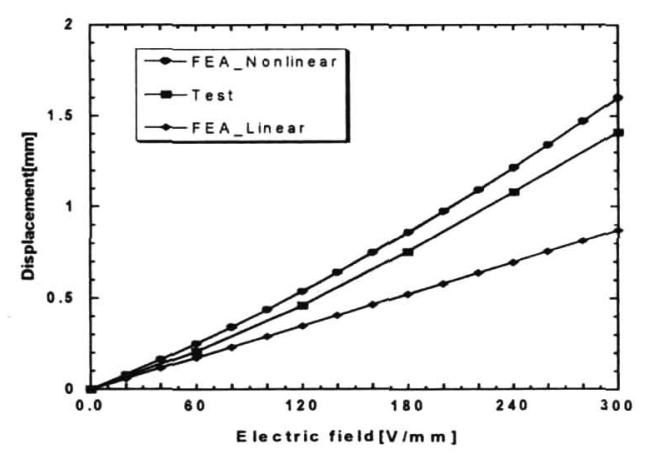

Fig. 14. Actuation displacement of bimorph beam

하는 전단변형(shear deformation)과 인가 전압 과 응력에 의해 강성이 변화하는 압전재 자체의 특성에 기인하는 것으로 판단된다.

\section{V. 결 론}

본 연구에서는 압전 작동기의 비선형 거동이 주로 압전 재료의 재료 비선형성에 기인함을 밝 혔으며, 실험으로, 압전 재료 $3203 \mathrm{HD}$ 의 재료비선 형 거동을 전기장과 응력의 함수로 표현하여, 유 한요소해석에 적용하여 수치적으로 모사하였다. 이상의 과정을 바이모프 보 작동기의 해석에 적 용하여, 예측된 변위와 측정 변위가 잘 일치함을 확인하였다. 따라서, 압전 재료 $3203 \mathrm{HD}$ 의 재료비 선형 특성이 충분히 측정되었음을 알 수 있다.

\section{후 기}

본 연구는 과학기술부의 2001년도 국가지정연구실 사업의 지원을 받아 수행되었으며, 이에 감사드립니다.

\section{참고문헌}

[1] G. H. Haertling, "Rainbow Actuators and Sensors: A New Smart Technology," Proc. of SPIE Conference, San Diego, CA, Vol 3040, 3-4 March, 1997, pp.81 92.

[2] K. M. Mossi and R. P. Bishop, "Characterization of Different Types of High Performance THUNDER," Proc. of SPIE Conference, paper number 3675-05, Newport Beach, CA, 1-5 March, 1999.

[3] R. Hellbaum, R.G. Bryant, and R.L. Fox, "Thin Layer Composite Unimorph Ferroelectric Driver and Sensor," United States Patent No. 5,632,841, 1997.

[4] K.J. Yoon, S. Shin, and H.C. Park, "Design and Manufacturing of Lightweight Piezo-composite Curved Actuator," Smart Materials and Structures (in print, 2002).

[5] Sangki Lee, Byung Chan Cho, Hoon Cheol Park, Kwang Joon Yoon, Nam Seo Goo, "Analysis of multi-layered actuators using an assumed strain solid element," Materials Chemistry and physics, Vol. 75, No. 1-3, pp.174-177, April, 2002.

[6] E.F. Crawley and K.B. Lazarus, " Induced Strain Actuation of Isotropic and Anisotropic Plates." AIAA Journal, Vol. 29(5), 1991, 944 951.

[7] R.P. Thornburgh and A. Chattopadhyay, "Nonlinear Actuation of Smart Composites Using a Coupled Piezoelectirc-Mechanical Model," Smart Mater. Struct., October, 2001, pp.743 749 .

[8] Quiming M. Zhang and Jianzhong Zhao, ."Electromechanical Properties of Lead Zirconate Titanate Piezoceramics Under the Influence of Mechanical Stresses," IEEE Transactions on Ultrasonics, Ferroelectrics and Frequency control, Vol. 46(6), November, 1999, pp.1518 1526.

[9] 조병찬, 이상기, 박훈철, 윤광준, 구남서, "3차원 가정변형률 솔리드 요소를 이용한 압전작 동기/감지기 해석," 한국항공우주학회지, 제 30 권, 제2호, pp.67-74, 2002. 